\title{
A challenging welcome to the new journal
}

\author{
Jorge Serrano 1
}

Published online: 22 February 2017

(C) The Japan Section of the Regional Science Association International 2017

This journal's name conveys its far reaching purpose: Asia-Pacific Journal of Regional Science. If we take as we should Asia-Pacific as one of the largest world regions, we realize one of its primary goals. Yet this is not enough. We must understand that ever since last decades, Asia-Pacific is being perceived as a highly dynamic region that matches the Atlantic macro region. Moreover-and this is an essential key to comprehend the journal's right time to be born-far beyond any concern to see a parallelism with world regions, would it be too much to say that probably Asia-Pacific is to be understood today as the most strategic macro region of the world? If we take the hard political and economic, as well as educational, demographic or cultural facts of recent times, we can see by any means that this journal can claim to be a strategic one.

Let us just consider several of the emerging trends in the Western world. There is first of all a new USA President strongly pushing the country back inside itself to the point of breaking into pieces almost any multilateral approach to world issues; whereas simultaneously a growing trend is emerging in Europe like the Brexit in England, the conservative 'Front National' with Marine Le Pen in France, Norbert Hofer's far-right nationalistic Friedenspartei (Freedom Party) in Austria, Netherland's Geert Wilders tough xenophobic PVV (Freedom Party), neo-Nazism in Germany and other European countries; plus the pressing European Union problems with its currency and its burning times with migrants coming by flocks-and so forth. Whereas in our side, we can read such trends as well as an opportunity for Asia-Pacific on both sides of the Pacific Ocean-yet mostly in Asia and Latin America-to push forward new macro regional approaches to international relationships. Is it too far if we say on such grounds that the world is beginning

Jorge Serrano

jrsmhi@gmail.com

1 Centro Regional de Investigaciones multidisciplinarias, Universidad Nacional Autonoma de Mexico, Mexico City, Mexico 
to delineate a new turning-point epoch? Maybe... Yet such issues do point towards new horizons. And the present journal appears right at this juncture. This is why we said the journal has the chance to become a really strategic conveyor of ideas and proposals to contribute to such promising epoch. Hope this journal will fulfill such role. But the real answer is to be given by the contributions of concerned thinkers in Asia as well as in Latin America-and of course of those of North America, Europe, Africa and the Middle East - thinkers as you, respectful reader, who are invited to contribute.

Moreover, we on both Pacific sides-including those of the American Union and Canada not agreeing with the new USA protectionist and closed country policyare not ready to accept that under the watchword of 'making the US great again', all of us with the rest of the world should constringe our potential to submit it to the USA protection priorities? Of course most of the world population is highly unsatisfied with the neoliberal approach to globalization, yet this is quite the opposite to a global world becoming really global due to its commitment to inclusiveness as well as innovation, social equity as well as education, and one that allows highest priority not to GDPs but rightly to a full-fledged social and personal life quality primarily for all, not for a single country regardless of how big it is. The space provided by this new journal is not only open to argue why such a reductionist approach is unacceptable but also and mostly to put forward fresh approaches to key issues of the present/future times, so as to give an opportunity to the forth emerging epoch. 